\section{NSAIDs in axial spondyloarthritis: to be continued...?}

\author{
G Varkas, ${ }^{1,2} \mathrm{~F}$ Van den Bosch ${ }^{1}$
}

Phenylbutazone was discovered in 1946 and promptly exhibited efficacy in various rheumatic diseases in the early 1950 s. Its efficacy on pain and general well-being was especially present in ankylosing spondylitis (AS), which was then known as 'rheumatoid spondylitis'. ${ }^{2}$ However, even in the early days, non-steroidal antiinflammatory drugs (NSAIDs) were not considered harmless drugs, as the toxic properties on bone marrow or the gastrointestinal tract, and the appearance of oedema or skin rash, although commonly reversible, were already apparent from the start. Up until now, a various range of NSAIDs have taken centre stage and have been the cornerstone of treatment of patients with spondyloarthritis $(\mathrm{SpA}) .^{3} 4$ Despite the common use of these drugs for almost seven decades, there are still a number of unanswered questions, such as which type of NSAIDs we should preferentially use in axial SpA (AxSpA) and whether these agents should be given continuously or on demand.

All NSAIDs are effective antiinflammatory drugs because of their ability to inhibit the biosynthesis of prostaglandins at the level of the cyclo-oxygenase (COX) enzyme; however, this mode of action also explains a number of side effects. While selective COX-2 inhibitors have claimed to induce fewer side effects through the omission of COX-1 inhibition, large meta-analyses have failed to demonstrate this superiority of COX selectivity in vascular and complicated gastrointestinal outcomes compared with conventional NSAIDs. ${ }^{5}{ }^{6}$ Furthermore, head-to-head comparisons of efficacy in AxSpA regarding the available NSAIDs are scarce. In AS, the treatment effect of piroxicam $20 \mathrm{mg}$, meloxicam $15 \mathrm{mg}$ and meloxicam $22.5 \mathrm{mg}$ did not differ significantly after 1 year of treatment regarding the patient's overall assessment, ${ }^{7}$ and Sieper et $a l^{8}$

\footnotetext{
'Department of Rheumatology, Ghent University Hospital, Ghent, Belgium; ${ }^{2}$ Molecular Immunology and Inflammation Unit, VIB Inflammation Research Center, Ghent University, Ghent, Belgium

Correspondence to Professor F Van den Bosch, Department of Rheumatology, Ghent University Hospital, De Pintelaan 185, Ghent 9000, Belgium; Filip.vandenbosch@ugent.be
}

reported that the efficacy of diclofenac compared with celecoxib was non-inferior regarding symptom relief. In contrast, other studies have demonstrated superior efficacy of etoricoxib compared with naproxen regarding spinal pain, disease activity and function. ${ }^{9} 10$ Nevertheless, a recent meta-analysis reported comparable short-term efficacy for all NSAIDs in active AS. ${ }^{11}$ Besides pain relief and suppression of inflammation, treatment goals in AxSpA have also focused on the potential deceleration-and preferably the arrest-of structural damage. The primary choice of NSAID in pain relief and modulation of radiographic progression has remained ambiguous and the need for chronic NSAID therapy in patients with SpA has been the reason for debate between patients and clinicians, and also among clinicians themselves.

Sieper et $a l^{12}$ adds challenging data to our knowledge of continuous versus intermittent NSAID intake on radiographic progression after 2 years in AS with the Effects of NSAIDs on RAdiographic Damage in Ankylosing Spondylitis (ENRADAS) trial. The ENRADAS trial provides us with a prospective trial of high quality with transparent statistical analysis, in a clinically homogeneous population with well-defined NSAID intake. In 2005, Wanders et $a l^{13}$ published a landmark paper, demonstrating that continuous intake of NSAIDs yielded a better outcome regarding structural damage over a 2-year period, compared with intermittent NSAID use. The Wanders trial has impacted clinical practice, as this was the first prospective randomised controlled trial (RCT) addressing a possible beneficial effect of continuous NSAID intake, regardless of patient symptoms and flares. The favourable effect of NSAIDs on radiographic progression in AS had already been postulated in a small retrospective study by Boersma. ${ }^{14}$ Later on, a few years after the study by Wanders et al, a retrospective analysis within the German Spondyloarthritis Inception Cohort (GESPIC) cohort found an association between higher NSAID intake and less radiographic progression. However, this was based on a NSAID index of $\geq 50$, which is the mean daily intake of the patient expressed as the percentage of the optimal daily dose of NSAIDs during the period of interest, rather than a true continuous intake. ${ }^{15} 16$ In contrast, in a multivariate analysis by Haroon et $a l,{ }^{17}$ NSAID intake was not associated with radiographic progression in AS, regardless of systemic inflammation.

Both in the GESPIC cohort and in the subanalysis by Kroon et $a l^{18}$ within the same study population described in the paper by Wanders et al, this structural effect was mainly attributable to an effect in patients with elevated inflammatory parameters. ${ }^{15}$ Due to these recent findings, the idea grew among rheumatologists that continuous intake of NSAIDs could be proposed in patients with a high inflammatory burden, regardless of their clinical symptoms. At present, extrapolation to non-radiographic $\mathrm{AxSpA}$ is not exceptional in clinical practice, although this effect has not been demonstrated in early disease. ${ }^{15}$

The investigators of the ENRADAS trial compared diclofenac $150 \mathrm{mg}$ daily with on-demand NSAID intake in a numerically equivalent sample of patients with AS, but could not demonstrate a difference in radiographic progression between continuous or intermittent intake of NSAID, not even when considering the subgroups of patients that had been identified previously as more prone to radiographic progression, such as patients with elevated C-reactive protein, baseline syndesmophytes or smokers. $^{12} 17 \quad 19$ In fact, although not significant, a numerically higher progression was seen in the patients with continuous intake. Another recent study by Maksymowych et $a l^{20}$ has also identified the presence of inflammation of the spine on MRI as a risk factor for radiographic progression. However, data on baseline MRI inflammation are lacking in both prospective trials and consequently may have been a potential drawback in patient stratification within the trials and patient comparability across the trials. The ENRADAS trial describes a modified Stoke Ankylosing Spondylitis Spine Score progression of $1.3(95 \%$ CI 0.7 to 1.9$)$ in the continuous intake group compared with the on-demand group, in which 0.8 (95\% CI 0.2 to 1.4) progression was observed. However, Wanders et al detected a progression of $0.4( \pm 1.7)$ in the group with continuous intake compared with 1.5 $( \pm 2.5)$ in patients on demand, which is more or less the opposite. In contrast to the use of a classic NSAID, such as diclofenac, the trial by Wanders et $a l^{13}$ employed the COX-2-selective agent celecoxib.

These findings challenge the underlying idea that the deceleration of structural 
damage would be an overall NSAID class effect. The question could be raised whether a possible differential effect of COX-2-selective versus conventional NSAIDs on bone is present, and more specifically the formation of syndesmophytes. There is some evidence of this differential effect of NSAIDs in rodents, while in humans, this differentiation has been studied in the field of heterotopic bone ossification (HO) and fracture healing. Yet, these results are equivocal. Provided that research in these other conditions of new bone formation would serve as a model for syndesmophyte formation in AS, literature states that indomethacin, ketolorac and naproxen would be more effective in the prevention of bone formation. On the other hand, piroxicam, flurbiprofen and rofecoxib would be ineffective. ${ }^{21-25}$ The published trials regarding celecoxib exhibited contradictory results. ${ }^{26} 27$ In conclusion, to date, meta-analysis could not support a differential effect of NSAIDs on $\mathrm{HO},{ }^{28}$ and it is clear that the effect of NSAIDs on bone formation in patients with AS-whether conventional or COX-2-selective-has yet to be uncovered.

Second, we must take into account that the aforementioned results of Wanders et al might be numerical findings, rather than true effect. In this regard, the rather limited statistical effect size of 0.07 has been pointed out by Guellec et al. ${ }^{29}$ Additionally, although continuous intake was defined as daily intake in both trials, the NSAID indexes in both RCTs are quite different. In the trial by Sieper et al, the NSAID index in the continuous and on-demand group was 75 and 44, respectively. However, the difference in overall NSAID intake between continuous and on-demand intake in the trial by Wanders et al can be calculated as being respectively $60.75(243 / 400)$ and 50.25 (201/ $400)$, which represents a rather marginal difference between the treatment groups. One could hypothesise that a greater difference in NSAID intake over time should have amplified the previous observed effect, but this is definitely not supported by the findings of the ENRADAS study.

Up until now, only one prospective RCT pointed towards a more favourable effect of continuous NSAID intake on radiographic progression; the new data from a comparable, well-designed RCT, fail to confirm this. Considering these conflicting data, there is currently insufficient evidence that continuous intake of NSAIDs would alter the radiographic progression in AS over a 2-year time period compared with intermittent use. It remains to be demonstrated whether this effect might be present after a longer follow-up, comparable to the data with antitumour necrosis factor- $\alpha$ (anti-TNF- $\alpha$ ) agents, which were considered disappointing in the light of the prior NSAID results. $^{30}$ Due to the inability of anti-TNF- $\alpha$ to slow down radiographic progression over 2-4 years, the hypothesis was generated that NSAIDs exerted their effect on bone formation through another mode of action than the resolution of inflammatory lesions. However, in the light of these novel findings, both drugs might display a similar effect on radiographic progression through modulation of inflammation.

A final, but important consideration that has to be taken into account when discussing continuous versus on-demand NSAID treatment, is the issue of feasibility of such an approach in daily practice. A small prospective cohort study in AxSpA-studying the effect of continuous optimal NSAID intake on bone marrow oedema of the sacroiliac joints on MRIhas addressed the difficulties of maintaining a continuous full-dose NSAID, even in patients with symptomatic AxSpA. Although the mandatory intake of NSAIDs was only 6 weeks, one-third of the patients were either not compliant or experienced side effects that limited continuous intake. ${ }^{31}$ Therefore, achieving compliance in asymptomatic patients for prevention of structural damage might be an illusion and currently insufficiently substantiated by evidence.

At present, NSAIDs remain the cornerstone of first-line symptomatic treatment in patients suffering from $\mathrm{AxSpA}$. It is self-evident that the decision whether to use NSAIDs continuously or on demand can be driven by multiple considerations, independent of a potential structuremodifying effect. Beside obvious symptom relief, this anti-inflammatory treatment might facilitate regular physiotherapy, which is also recognised as an important part of disease management. We may also not have grasped all the beneficial consequences of adequate control of chronic inflammation on the global burden of the disease. For example, Bakland et al ${ }^{32}$ showed more cardiovascular mortality, which was attributed to higher inflammatory load, in patients with AS who had taken NSAIDs less than once a month (OR 4.35). In another recent publication, Haroon et $a l^{33}$ found a comparable 'protective' effect in a population-based study, as the use of NSAIDs and statins was associated with a decreased risk for vascular mortality in patients with AS.
The new data by Sieper et al challenge the notion that continuous antiinflammatory treatment could have a potential structure-modifying effect, and prompt the clinician, who has to decide on a specific treatment strategy that involves NSAIDs, to be guided by symptoms and objective measures of inflammation.

Contributors Both GV and FVB have substantially contributed to the content and the interpretation of data. Final approval of the version has been published by GV and FVB.

Competing interests None declared.

Provenance and peer review Commissioned; externally peer reviewed.

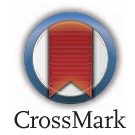

To cite Varkas G, Van den Bosch F. Ann Rheum Dis 2016;75:1423-1425.

Received 4 January 2016

Accepted 2 February 2016

Published Online First 26 February 2016

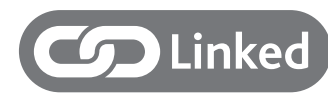

- http://dx.doi.org/10.1136/annrheumdis-2015207897

Ann Rheum Dis 2016;75:1423-1425.

doi:10.1136/annrheumdis-2015-208194

\section{REFERENCES}

1 Steinbrocker O, Berkowitz S, Ehrlich M, et al. Phenylbutazone therapy of arthritis and other painful musculoskeletal disorders. J Am Med Assoc 1952;150:1087-91.

2 Kidd EG, Boyce KC, Freyberg RH. Clinical studies of phenylbutazone (butazolidin) and butapyrin (irgapyrin) in rheumatoid arthritis, rheumatoid spondylitis, and gout. Ann Rheum Dis 1953;12:20-4.

3 van der Heijde D, Sieper J, Maksymowych WP, et al. 2010 Update of the international ASAS recommendations for the use of anti-TNF agents in patients with axial spondyloarthritis. Ann Rheum Dis 2011;70:905-8.

4 Braun J, van den Berg R, Baraliakos X, et al. 2010 update of the ASAS/EULAR recommendations for the management of ankylosing spondylitis. Ann Rheum Dis 2011;70:896-904.

5 Bhala N, Emberson J, Merhi A, et al., Coxib and traditional NSAID Trialists' (CNT) Collaboration. Vascular and upper gastrointestinal effects of non-steroidal anti-inflammatory drugs: meta-analyses of individual participant data from randomised trials. Lancet 2013:382:769-79.

6 Cannon CP, Curtis SP, FitzGerald GA, et al. Cardiovascular outcomes with etoricoxib and diclofenac in patients with osteoarthritis and rheumatoid arthritis in the Multinational Etoricoxib and Diclofenac Arthritis Long-term (MEDAL) programme: a randomised comparison. Lancet 2006;368:1771-81.

7 Dougados M, Gueguen A, Nakache JP, et al. Ankylosing spondylitis: what is the optimum duration of a clinical study? A one year versus a 6 weeks 
non-steroidal anti-inflammatory drug trial.

Rheumatology (Oxford) 1999;38:235-44.

8 Sieper J, Klopsch T, Richter M, et al. Comparison of two different dosages of celecoxib with diclofenac for the treatment of active ankylosing spondylitis: results of a 12-week randomised, double-blind, controlled study. Ann Rheum Dis 2008;67:323-9.

9 van der Heijde D, Baraf HS, Ramos-Remus C, et al. Evaluation of the efficacy of etoricoxib in ankylosing spondylitis: results of a fifty-two-week, randomized, controlled study. Arthritis Rheum 2005;52:1205-15.

10 Peloso PM, Gammaitoni A, Smugar SS, et al. Longitudinal numbers-needed-to-treat (NNT) for achieving various levels of analgesic response and improvement with etoricoxib, naproxen, and placebo in ankylosing spondylitis. BMC Musculoskelet Disord 2011;12:165.

11 Wang R, Dasgupta A, Ward MM. Comparative efficacy of non-steroidal anti-inflammatory drugs in ankylosing spondylitis: a Bayesian network meta-analysis of clinical trials. Ann Rheum Dis 2016;75:1152-60.

12 Sieper J, Listing J, Poddubnyy D, et al. Effect of continuous versus on-demand treatment of ankylosing spondylitis with diclofenac over 2 years on radiographic progression of the spine: results from a randomised multicentre trial (ENRADAS). Ann Rheum Dis 2016;75:1438-43.

13 Wanders A, Heijde D, Landewé R, et al. Nonsteroidal antiinflammatory drugs reduce radiographic progression in patients with ankylosing spondylitis: a randomized clinical trial. Arthritis Rheum 2005;52:1756-65.

14 Boersma JW. Retardation of ossification of the lumbar vertebral column in ankylosing spondylitis by means of phenylbutazone. Scand J Rheumatol 1976;5:60-4.

15 Poddubnyy D, Rudwaleit $M$, Haibel $H$, et al. Effect of non-steroidal anti-inflammatory drugs on radiographic spinal progression in patients with axial spondyloarthritis: results from the German
Spondyloarthritis Inception Cohort. Ann Rheum Dis 2012;71:1616-22.

16 Dougados M, Simon P, Braun J, et al. ASAS recommendations for collecting, analysing and reporting NSAID intake in clinical trials/ epidemiological studies in axial spondyloarthritis. Ann Rheum Dis 2011;70:249-51.

17 Haroon N, Inman RD, Learch TJ, et al. The impact of tumor necrosis factor alpha inhibitors on radiographic progression in ankylosing spondylitis. Arthritis Rheum 2013;65:2645-54.

18 Kroon $\mathrm{F}$, Landewé $\mathrm{R}$, Dougados $\mathrm{M}$, et al. Continuous NSAID use reverts the effects of inflammation on radiographic progression in patients with ankylosing spondylitis. Ann Rheum Dis 2012;71:1623-9.

19 Poddubnyy D, Haibel H, Listing J, et al. Baseline radiographic damage, elevated acute-phase reactant levels, and cigarette smoking status predict spinal radiographic progression in early axial spondylarthritis. Arthritis Rheum 2012;64:1388-98.

20 Maksymowych WP, Chiowchanwisawakit P, Clare T, et al. Inflammatory lesions of the spine on magnetic resonance imaging predict the development of new syndesmophytes in ankylosing spondylitis: evidence of a relationship between inflammation and new bone formation. Arthritis Rheum 2009;60:93-102.

21 Reuben SS. Effect of nonsteroidal anti-inflammatory drugs on osteogenesis and spinal fusion. Reg Anesth Pain Med 2001;26:590-1.

22 Adolphson $\mathrm{P}$, Abbaszadegan $\mathrm{H}$, Jonsson $\mathrm{U}$, et al. No effects of piroxicam on osteopenia and recovery after Colles fracture. A randomized, double-blind, placebo-controlled, prospective trial. Arch Orthop Trauma Surg 1993;112:127-30.

23 Davis TR, Ackroyd CE. Non-steroidal anti-inflammatory agents in the management of Colles fractures. Br J Clin Pract 1988;42:184-9.

24 Sagi HC, Jordan CJ, Barei DP, et al. Indomethacin prophylaxis for heterotopic ossification after acetabular fracture surgery increases the risk for nonunion of the posterior wall. $J$ Orthop Trauma 2014;28:377-83.

25 Burd TA, Hughes MS, Anglen JO. Heterotopic ossification prophylaxis with indomethacin increases the risk of long-bone nonunion. J Bone Joint Surg Br 2003;85:700-5.

26 Saudan M, Saudan P, Perneger T, et al. Celecoxib versus ibuprofen in the prevention of heterotopic ossification following total hip replacement: a prospective randomised trial. J Bone Joint Surg Br 2007;89:155-9.

27 Romanò $C L$, Duci $\mathrm{D}$, Romanò $\mathrm{D}$, et al. Celecoxib versus indomethacin in the prevention of heterotopic ossification after total hip arthroplasty. J Arthroplasty 2004;19:14-18.

28 Kan SL, Yang B, Ning GZ, et al. Nonsteroidal anti-inflammatory drugs as prophylaxis for heterotopic ossification after total hip arthroplasty: a systematic review and meta-analysis. Medicine (Baltimore) 2015;94:e828.

29 Guellec D, Nocturne G, Tatar Z, et al. Should non-steroidal anti-inflammatory drugs be used continuously in ankylosing spondylitis? Joint Bone Spine 2014;81:308-12.

30 Baraliakos $X$, Haibel H, Listing J, et al. Continuous long-term anti-TNF therapy does not lead to an increase in the rate of new bone formation over 8 years in patients with ankylosing spondylitis. Ann Rheum Dis 2014;73:710-15.

31 Varkas G, Jans L, Cypers H, et al. Six-week treatment of axial spondyloarthritis patients with an optimal dose of NSAIDs: early response to treatment in signal intensity on magnetic resonance imaging of the sacroiliac joints. Arthritis Rheumatol 2015 [epub ahead of print 16 Oct 2015].

32 Bakland G, Gran JT, Nossent JC. Increased mortality in ankylosing spondylitis is related to disease activity. Ann Rheum Dis 2011;70:1921-5.

33 Haroon NN, Paterson JM, Li P, et al. Patients with ankylosing spondylitis have increased cardiovascular and cerebrovascular mortality: a population-based study. Ann Intern Med 2015;163:409-16. 